\title{
Normative Naturalism on Its Own Terms
}

\author{
Pekka Väyrynen*
}

Received: 6 November 2020 / Accepted: 9 April 2021

\begin{abstract}
Normative naturalism is primarily a metaphysical doctrine: there are normative facts and properties, and these fall into the class of natural facts and properties. Many objections to naturalism rely on additional assumptions about language or thought, but often without adequate consideration of just how normative properties would have to figure in our thought and talk if naturalism were true. In the first part of the paper, I explain why naturalists needn't think that normative properties can be represented or ascribed in wholly nonnormative terms. If so, certain prominent objections to normative naturalism fail. In the second part, I consider the objection that normative properties are "just too different" from (other) natural properties to themselves be natural properties. I argue that naturalists have no distinctive trouble making sense of thought and talk involving forms of "genuine" or "authoritative" normativity which can drive a non-question-begging form of the objection.
\end{abstract}

Keywords: Authoritative normativity; normative concepts; normative naturalism; one-term naturalism; practical normativity.

* University of Leeds

(iD) https://orcid.org/0000-0003-4066-8577

The School of Philosophy, Religion and History of Science, University of Leeds, Leeds, LS2 9JT, United Kingdom.

$\triangle$ p.vayrynen@leeds.ac.uk

() The Author. Journal compilation (C) The Editorial Board, Organon F.

This article is distributed under the terms of the Creative Commons Attribution-NonCommercial 4.0 International Public License (CC BY-NC 4.0). 


\section{Introduction}

Normative naturalism is, to a first approximation, the view that there are normative facts and properties, and these fall into the class of natural facts and properties. ${ }^{1}$ Specific forms of naturalism may come with additional semantic, epistemological, or other commitments. At its core, however, normative naturalism is a metaphysical doctrine. But many objections to naturalism rely on additional assumptions about language or thought. My aim in this paper is to make two (largely distinct) contributions to debates about how normative properties might figure in language and thought if normative naturalism is true.

The first part of the paper focuses on an assumption I'll call Non-Normative Representability (NNR). To a first approximation, NNR says that nothing counts as a natural property unless it can be expressed, or represented, or ascribed with wholly non-normative terms or concepts. Paradigmatic non-normative terms include 'is tubular', 'has low air pressure', and 'promotes survival'. The upshot of NNR for normative properties is that their being natural depends on whether they can be ascribed not only by normative terms or concepts, such as 'ought', 'wrong', and 'good', but also by non-normative terms or concepts. Many naturalists accept this. But Nicholas Sturgeon (2003) has argued that NNR isn't a commitment of normative naturalism as such. The point is worth laboring because it has important ramifications, but it keeps getting ignored. I'll improve on Sturgeon's statement of NNR a bit and illustrate what's at stake by explaining how a wide range of objections to normative naturalism presuppose NNR (§2). I'll then offer reasons, Sturgeon's and my own, why the truth of normative naturalism doesn't require NNR and why NNR is questionable enough for naturalists to have reason to keep their distance since they can (§3). I'll also discuss why this needn't mean losing our grip on the notion of a natural property $(\S 4)$.

1 I use 'normative' to cover both the deontic and the evaluative. I'll understand properties as entities that characterize the objects which have them. I use 'property' broadly to cover also relations. I'll take a fact to be an entity, a state of affairs, which concerns objects exemplifying properties or standing in relations.

Organon F 28 (3) 2021: 505-530 
The second part of the paper offers a slightly sideways approach to the "just too different" objection to normative naturalism. Many critics of naturalism think that especially properties involving "robust" or "authoritative" normativity are too different from (other) natural properties to also be natural properties. I'll first suggest that the objection loses some of its force if normative naturalism isn't committed to NNR and note difficulties in specifying the notion of "genuine" or "authoritative" normativity which is the objection's primary concern ( 55$)$. Some notions of such authority are too weak to support the objection, but many stronger notions are questionbegging. I'll then pick a particular authoritatively normative concept which falls somewhere in the middle to give a proof of concept that naturalists have no distinctive trouble making sense of thought and talk involving authoritative normativity $(\S 6)$. This strategy doesn't require rejecting NNR, but avoids some headaches without it. Thus, I'll focus throughout on forms of normative naturalism which needn't accept NNR. ${ }^{2}$

\section{Non-normative representability and objections to naturalism}

To get a better grip on Non-Normative Representability and what's at stake in it, it's instructive to consider some objections to normative naturalism which presuppose NNR.

The observation that discussions of normative naturalism often presuppose NNR isn't original to me. In its standard interpretations, G. E. Moore's "open question" argument implies that 'good' doesn't stand for a natural property, roughly on the grounds that it cannot be analyzed or defined in any wholly non-normative terms (Moore 1903, ch. 1). In a rich discussion of Moore's arguments against naturalism, Sturgeon notes that we know from the beginning that 'good' is coreferential with itself. It's only if you assume from the outset that 'good' doesn't stand for a natural property in its own right that an argument that 'good' is indefinable shows that 'good'

2 I won't consider "analytic" naturalism. This implies NNR, since it says that any normative predicate is analytically equivalent with, and in principle replaceable by, a descriptive, non-normative predicate that ascribes the same property. For a sophisticated contemporary form of this view, see (Jackson 1998). 
isn't coreferential with any term whatever standing for a natural property. ${ }^{3}$ Sturgeon offers a conjecture regarding why generations of critics have missed that the open question argument begs the question in this way: "I think that the answer must be that they are relying on an assumption about natural properties that seems to them so obvious as not to need stating: namely, that nothing counts as a natural property unless we have some non-ethical terminology to represent it" (Sturgeon 2003, 536). Sturgeon here states a restricted thesis. If we generalize his talk of "non-ethical terminology" to non-normative terminology, we get NNR as a claim about language. I'll understand it specifically as a claim about natural languages that can be used by human beings. A further generalization would extend it to a claim about concepts. I'll take NNR to be this more general claim.

Sturgeon's statement of NNR can be improved on in two further respects. First, the above statement makes it sound like NNR requires that we already have terminology to represent all natural properties in wholly non-normative terms. But one could well grant that we don't yet have such terminology. This is why I initially introduced NNR as the claim that nothing counts as a natural property unless it can be expressed, or represented, or ascribed using wholly non-normative terms or concepts. Accordingly, in what follows I'll understand NNR as saying what must be possible in principle if a property is a natural one. ${ }^{4}$

Second, Sturgeon doesn't say what counts as representing a property, or what counts as representing it in non-normative terms. Terms like 'represent', 'ascribe', and 'express' will likely function as technical terms here. Suppose for illustration that rightness is a natural property. It shouldn't be

3 Sturgeon (2003, 536). This is a common assumption. William FitzPatrick, for instance, claims that "any tempting natural specification of the referent of 'good' will focus on something such as human needs, in which we naturally take an interest" (2008, 182). This clearly assumes NNR. FitzPatrick then notes that goodness is the sort of property that merits our interest and asks "what objective natural fact or facts would such a fact about a natural cluster property's meriting a certain practical response consist in?" (FitzPatrick 2008, 182). The naturalist can say "The fact that it's good' or 'The fact that it merits such a response'.

4 In some other passages, Sturgeon seems to have in mind a claim about what's possible in principle.

Organon F 28 (3) 2021: 505-530 
enough for rightness to satisfy NNR that it can be denoted by such nonnormative expressions as 'the property we'll be thinking about in class today' or 'the Pope's favorite property'. ${ }^{5}$ (That normative properties can be denoted in this way doesn't show normative non-naturalism to be false!) Giving a satisfactory account of why this should be so is tricky, though. But one intuitive difference is that the above descriptions don't pick out rightness "in their own right" in some sense, whereas 'right' does. ${ }^{6}$ This difference can be seen also in the following example from Matti Eklund: "Suppose that an alien linguistic community introduces into their language a word - 'thgir' - with the stipulation that 'thgir' is to ascribe the property that our 'right' ascribes, but this community does not in any way use their word 'thgir' normatively" (Eklund 2017, 75). The status of rightness as a natural property shouldn't depend on whether a predicate like 'thgir' is possible. So again NNR should require that if a non-normative term or concept ' $\mathrm{F}$ ' ascribes some property $\mathrm{N}$, it does so in its own right. Introducing 'thgir' requires appeal to 'right', so it fails this condition. ${ }^{7}$ I'm not sure just how to spell out the relevant notion of "in its own right", but I hope the basic idea is intuitive enough. This condition on ascription or representation doesn't imply that if NNR is true, then normative concepts or properties are reducible to ones expressible in wholly non-normative terms - at least not for any notion of reduction stronger than necessary equivalence. Nor does NNR settle by fiat the question whether the relevant notion of being normative is primarily a feature of terms and concepts, or of the facts and properties they express. ${ }^{8}$

5 Jackson $(1998,119)$ distinguishes "denoting" a property from "ascribing" it in this kind of way.

${ }_{6}$ Whether 'good' or 'right' ascribes a normative property may vary with context. Even so, the kind of contextual input that's involved in determining their reference looks different from that involved in determining when 'the property we'll be thinking about in class today' denotes rightness.

7 The same point may apply to the idea that if (as many naturalists think) normative properties play a causal role and if $\mathrm{R}$ is the causal role of rightness, then rightness can be represented non-normatively as 'the property that fills causal role R'. For we may have to use 'right' to specify R.

8 The question will pop up again in $\$ 6$. For the general debate, see e.g. (Roberts 2013) and (Eklund 2017, chs. 4-5). (Finlay 2019) is a helpful overview of various 
Many objections to naturalism question the possibility of ascribing normative properties in non-normative terms which satisfy these conditions. Moore's illustrations of the open question argument are like this. Another example is Derek Parfit's Triviality Objection against normative naturalism. Its core is that the central claims of normative naturalism must take the form of statements of identity between normative and natural properties, but no such claim can have all of the features, such as informativeness, required by the truth of normative naturalism (Parfit 2011, 344). One response is to argue that Parfit's objection can be met on its own terms (Dowell and Sobel 2017). But we might instead note that according to Parfit, the truth of normative naturalism requires informative identity statements of the form 'NORM=NAT', where 'NORM' is placeholder for a normative term and 'NAT' is a placeholder for a simple or complex expression that ascribes a natural property. He correctly points out that if normative naturalism is true, then 'NORM' ascribes a natural property. He also correctly points out that substituting 'NORM' for 'NAT' would make the identity statement uninformative. He concludes that an informative identity statement of this form requires that 'NAT' be a non-normative expression. So it's clear that Parfit accepts NNR, or at least attributes it to his target (see also Parfit 2011, 295). Suspend NNR, and normative naturalism doesn't require true informative identity statements of the form 'NORM=NAT'.

A more recent example is Matt Bedke's argument that normative naturalism makes normative cognition dispensable. By normative cognition, Bedke means thought and talk involving concepts or terms such as 'ought' or 'is good', whose occurrent tokenings have a special mode of presentation that involves a sense of "inherent, authoritative guidance" (Bedke 2021, 149). His worry is that normative naturalism makes this presentational quality accidental: it is "not needed to fit the job description of normative cognition-ascribing natural properties. That can be done with non-

things that 'normative' may mean when applied to concepts, judgments, properties, and more. Normative naturalists on both sides of NNR differ on whether the normative/non-normative distinction is primarily a distinction among concepts or properties.

Organon F 28 (3) 2021: 505-530 
normative (natural) cognition" (Bedke 2021, 150). ${ }^{9}$ The naturalist can agree that insofar as a sense of authoritative guidance is integral to our thought and talk about how to act and live, making it dispensable would be a problem. But again, NNR is crucial for raising the problem in the first place. Suspend NNR, and non-normative cognition isn't guaranteed to suffice for ascribing natural properties. Nor would it be an accident that if naturalism is true, normative cognition ascribes natural properties.

There are many other examples. For instance, normative naturalism is sometimes interpreted as saying that normative facts aren't further facts relative to non-normative facts (Rosen 2018, 157). But all it implies is that normative facts aren't further facts that come on the scene after the natural facts are fixed. This follows trivially, if normative facts are among the natural facts. I trust that readers familiar with debates over normative naturalism will recognize how widely those debates presuppose NNR. It would therefore be important to debates over normative naturalism if its truth didn't require NNR.

\section{Normative naturalism without non-normative representability}

Normative naturalism is at its core a metaphysical thesis about the nature of normative facts and properties: they are a kind of natural facts and properties. ${ }^{10}$ Naturalness in this sense isn't a feature of words or concepts that can be used to ascribe those properties. So the core thesis of normative naturalism doesn't involve a further thesis about the relation between two sets of terms, "normative" and "non-normative". This is so irrespective of whether being normative and being non-normative are (primarily) features of terms or concepts, or of facts or properties. So the truth of normative

9 This is how Bedke formulates his concern in relation to the "referential" function of normative concepts. For naturalists who appeal instead to a distinctive "nonreferential" function, see the references in note 26 .

10 Normative naturalism might have some semantic implications. Perhaps if killing is bad and that's a natural fact, then any sentence which represents this fact is true. This is hardly distinctive, though. 
naturalism doesn't depend on NNR. Naturalists need only claim that every normative fact is already a natural fact, irrespective of whether there's a non-normative way of representing that fact in addition to the normative way. (In $\S 4$ I'll discuss conceptions of a natural property which allow this possibility.) Jonathan Dancy $(2006,127)$ dubs this view "one-term naturalism", in contrast to "two-term naturalism" which endorses the further linguistic or conceptual commitments of NNR. ${ }^{11}$

Many naturalists do adopt the two-term naturalist project of identifying which natural properties are normative properties in non-normative terms (Railton 1986; Boyd 1988; Copp 1995). It's true, but trivial, that to be wrong is to be wrong. It would be non-trivial if to be wrong were to fail to maximally promote the objective interests of everyone, impartially considered (Railton 1986), or interfere with the flourishing of societies (Copp 1995), or destabilize cooperation (Sterelny and Fraser 2017). Property identifications like these are empirical hypotheses about which natural properties the normative properties are likely to be, given certain non-normatively characterizable functions which morality and other normative codes play in human life (Isserow ms). They invite the kinds of objections canvassed above. I'm not arguing against two-term naturalism. I simply note that defending such identifications isn't necessary to the truth of naturalism. Without NNR, those objections fall away. ${ }^{12}$

Sturgeon finds NNR "highly questionable: possibly false, and at the very least requiring defense" (Sturgeon 2003, 537). He appeals to the idea that normative naturalism isn't in the first instance a doctrine about languagenor, we might add, about thought. He also notes analogies which counsel caution about NNR. One is that physicalism about the mental doesn't require that mental states be representable, even in principle, in the language

11 Arguments for two-term naturalism might include arguments for the reducibility of normative properties (Railton 1986), arguments from supervenience (Jackson 1998), or arguments from requirements on coherent planning (Gibbard 2003). These arguments don't show that the truth of normative naturalism requires NNR.

12 An individual naturalist can of course go ahead defending an informative property identification if they consider that important on some further ground. Establishing some such identification just wouldn't be necessary to the truth of normative naturalism, but more like an add-on to your basic meal deal.

Organon F 28 (3) 2021: 505-530 
of physics (Sturgeon 2003, 537). Our account of how mental states can be physical states needn't take such a form. Another concerns "metaphysical" properties, including divine goodness. If they couldn't be represented in non-normative terms, that wouldn't disqualify them from being metaphysical properties. This gives us additional reason to "ask why a property's being natural should depend on this" (Sturgeon 2003, 540). We have no reason to suppose NNR is true because of something special about representing natural properties in particular. In a different context, Sturgeon notes that scientific progress involves introducing new terms for previously unrecognized properties all the time, and it's controversial whether this process of terminological innovation has an end, even in principle (Sturgeon 2006, 99).

More generally, it seems possible for natural properties to exceed even our best representational resources, non-normative or otherwise. Any natural language can have only countably many predicates, but natural properties might not be only countably many. Some natural properties might also be more fine-grained than what natural languages or human thought can represent. Examples might include the most maximally determinate values along certain continuous physical parameters. In general, any representation abstracts from some features of its object; otherwise it duplicates rather than represents the object. At least the latter point remains even if NNR requires only that for any natural property $\mathrm{N}$, there's a non-normative predicate in some or other natural language which ascribes $N$. These points matter because NNR seems to imply that if there are some properties which we're incapable of representing at all, those properties won't be natural. If a property's being natural depended on whether it can be represented in certain kind of way, why should properties that we can't represent be exempt from this requirement? Why not instead adopt a conception of a natural property which doesn't impose NNR-style representational conditions? We would in any case need such independent conditions for a property to be natural if we wanted to allow that the class of natural properties includes properties which we cannot represent.

The above points all concern natural properties of whatever kind, not specifically normative properties. They imply on very general grounds that whether normative properties fall into the class of natural properties doesn't 
depend on how those properties relate to non-normative representations. I don't take these considerations to establish that NNR is false. The matters are complex enough that it would be folly to take them as settled. For instance, it's plausible that all of the paradigmatic natural properties that we can represent are ones we can represent in non-normative terms. Perhaps this is best explained by NNR. ${ }^{13}$ People are likely to vary regarding whether the above considerations suffice to defeat that inference. But for my purposes I don't need to show that NNR is false, but only that it's questionable enough for normative naturalists to have reason to keep their distance since they can. I take the above to show this much. There may also be further worries about NNR as applied specifically to normative properties. One example would be if naturalists thought that some normative properties, such as wrongness, are somehow essentially normative. (However, such views are more commonly raised as objections to normative naturalism. I'll return to this in §5.) Another potential example is the view that the extensions of normative terms and concepts aren't unified under non-normative similarity relations. If this "shapelessness thesis" is compatible with normative naturalism, that might be another reason to worry about NNR. ${ }^{14}$

\section{Naturalness and non-normative representability}

One concern about divorcing normative naturalism from NNR is that we might lose our grip on the sense in which normative properties are supposed to be natural. How are normative properties supposed to fall into the class of natural properties, if not in virtue of how normative properties are related to properties which are fairly uncontroversially natural and can be ascribed in non-normative terms? The main issue for my purposes is this:

13 Thanks to a reviewer for this journal for pressing this response. They also worried that the most salient naturalistic accounts of reference-determination support a case for NNR. I don't think the issue is nearly as clear-cut, but cannot address this properly for reasons of space. (For one relevant point, see the end of $\S 6$.)

14 Väyrynen (2014) argues that the shapelessness thesis is compatible with ethical naturalism, doesn't require normative particularism, and can be explained by more general factors not specific to the normative.

Organon F 28 (3) 2021: 505-530 
one-term naturalism requires a conception of a natural property on which normative properties meet the conditions for naturalness directly, rather than in virtue of how our normative ways of representing them are related to non-normative representations. The good news is that none of the three most prominent accounts in metaethics of which properties are natural properties implies that any plausible normative naturalism must accept NNR. ${ }^{15}$

Suppose that any property that is such as to play a causal role in the natural world (or else figure in causal explanations of events or states of affairs) is a natural property. Whether something plays a causal role doesn't depend on how we describe it. So normative properties like goodness and wrongness qualify as natural in their own right if they play a causal role in the world, even if they cannot thereby be represented in wholly non-normative terms. Sturgeon suggests that "placing a property in a causal network is a way of saying something about which property it is, even if one lacks an explicit reduction for it" (Sturgeon 2006, 100). It's of course controversial whether normative properties meet this condition or its stronger sibling which requires an ineliminable causal or explanatory role. ${ }^{16}$ It's also controversial whether the satisfaction of the relevant explanatory condition by normative properties entails the metaphysical claims of normative naturalism (Sinclair 2011). But these aren't debates about whether a plausible normative naturalism must accept NNR.

Or, suppose a natural property is such that synthetic propositions about its instantiation aren't strongly a priori but are subject to empirical constraint (Copp 2003, 181; Boyd 1988). If normative properties met this condition, they would do so in their own right: the propositions to be tested would be propositions involving normative concepts. Specifying how propositions about the instantiation of a property can come to be known, and how their justification may be defeated, is again a way of saying something about which property it is. Whether our basic moral knowledge is strongly a priori is a familiar debate, of course. But it's not a debate about whether a plausible normative naturalism must accept NNR.

15 Copp (2003) and Väyrynen (2009) survey the main options relevant to metaethical debates.

16 For a classic exchange, see Sturgeon $(1985 ; 1986)$ vs. Harman (1986). 
Or, suppose that any property posited in the best scientific accounts of the world is natural (Shafer-Landau 2003, 59). In the case of morality, naturalists argue that there is an empirical discipline which deals with ethical matters and is no less apt to figure in the best scientific accounts of the world than psychology or sociology - namely, a discipline called ethics (Boyd 1988, 206-8; Sturgeon 2003, 553). ${ }^{17}$ If ethics had such a disciplinary status, then establishing principles linking non-normative properties to normative ones through first-order normative inquiry would be a way of saying something about which natural properties goodness and rightness are even if those connections aren't so robust as to satisfy NNR. It's of course controversial whether ethics has this kind of disciplinary status. But that's again not a debate about whether a plausible normative naturalism must accept NNR.

I conclude that the most prominent accounts of natural properties in debates about normative naturalism and non-naturalism don't imply that we'll lose our grip on the notion of a natural property if plausible forms of normative naturalism needn't accept NNR. So no new reason has emerged to treat NNR as a condition on the truth of normative naturalism.

\section{The "just too different" objection}

I'll now turn to the "just too different" (JTD) objection to normative naturalism. The objection has it that the things we represent in normative ways are, intuitively, just too different from the things we represent in nonnormative ways for them to be metaphysically of a kind. As Dancy puts it: "There remains a stubborn feeling that [normative] facts about what is right or wrong, what is good or bad, and what we have reason to do have something distinctive in common, and that this common feature is something

17 Several normative naturalists suggest that health is an evaluative concept which picks out a property that plays genuine explanatory roles (Bloomfield 2001; Sturgeon 2003, 553; Railton 2018, 51) and so there are uncontroversially naturalistic disciplines that deal with questions of value. This may require a view of "thick" concepts which is widely endorsed but which I myself find questionable (Väyrynen 2013; cf. Cline 2015). 
that a natural fact could not have" (Dancy 2006, 136). ${ }^{18}$ For instance, nothing can count as good or right unless it's something that we ought to be concerned to promote, or merits being given a certain kind of weight in deliberation, or the like. Paradigmatic natural facts - ranging from facts of physics and chemistry to non-normative facts about the colors of objects, the needs and desires of human and non-human animals, and the likearen't like that. So why think that facts with the kind of special importance that normative facts seem to have are metaphysically of a kind with paradigmatic non-normative natural facts which lack such importance?

The JTD objection can be raised against both one-term naturalism and two-term naturalism, since it relies on a contrast between properties represented in normative terms and properties represented in paradigmatically non-normative terms. But I suspect the objection derives some of its force from assuming that normative naturalism is committed to NNR. An intuitive contrast between paradigmatic non-normative natural properties and properties like rightness and wrongness is less compelling as an objection to normative naturalism if properties can be natural without conforming to non-normative paradigms like fermentation, color, need, or desire. That paradigmatic members of class $\mathrm{C}$ lack feature $\mathrm{F}$ does little by itself to show that $\mathrm{C}$ doesn't have a subclass whose members do have $\mathrm{F}$. The residual force of the objection depends on what counts as the kind of normative importance which is supposed to set normative facts apart from (other) natural facts. The more distinctive normative facts are from these other facts in this respect, the more forceful the concern.

Words like 'good', 'right', and 'ought' are often used to express forms of normativity which are naturalistically acceptable. These include norm-relative normativity characteristic of conventional norms (law, etiquette) and role obligations (such as what's required of teachers), kind-relative normativity (such as being a good toaster), and instrumental normativity. ${ }^{19}$

18 See also Nagel (1986, 138), FitzPatrick (2008, 179-82), Enoch (2011, 104-8), and Parfit (2011, 324-27). I won't be able to do justice to various nuances that can be found in these and other discussions of the just-too-different objection. For a helpful survey of the debate, see Paakkunainen (2017).

19 See e.g. (Paakkunainen 2017, 3) and the references therein. Not everyone thinks that these forms of non-categorical normativity are less puzzling than categorical 
These all involve standards such that if you fail to satisfy them, you're open to a certain kind of criticism. So if the special features that are supposed to make it implausible that normative properties fall into the class of natural properties were exhibited also by these normative properties, naturalists needn't worry. It's thus no surprise that the JTD objection tends to focus on a subclass of normative notions, such as being morally right or wrong, what one has normative reason to do, what one really ought to do, and the like. Their normativity has struck many as more "genuine" or "authoritative" than these other kinds of normativity.

Genuine or authoritative normativity is often characterized in terms of a distinctive role. Authoritatively normative concepts or judgments play some characteristic or essential role in deliberation. Authoritatively normative facts and properties have some characteristic or essential connection to decision and action. Proposals vary in terms of whether such connections are themselves normative. Either way, they are supposed to be different in kind from how both non-authoritative forms of normativity and non-normative notions may relate to deliberation and action. But it has proved difficult to pin down just what connections are meant to characterize robust or authoritative normativity. As Hille Paakkunainen notes: "There's currently little agreement on hallmarks of genuine normative importancebeyond, perhaps, certain intranormative connections between important normative notions" $(2017,9)$.

A common way to illustrate the JTD objection is to say that some normative facts, such as moral facts, are intrinsically significant in that any rational agent will have normative reason to respond accordingly. If such categorical reasons were a hallmark of the normative authority of morality, then normative naturalism would seem hard pressed to account for its authority. For many think that this kind of categorical normativity isn't compatible with a naturalistic world view. But we should distinguish two questions here. One is whether it's true that, no matter what the moral facts are like and what moral agents and their environments are like, any moral agent will by necessity have normative reason to act morally. The other is

normativity. How exactly this might relate to normative naturalism is a more complex issue than I can address here, however.

Organon F 28 (3) 2021: 505-530 
whether the idea that moral facts are categorically reason-giving is a firm datum whose denial automatically implies a significant loss of plausibility.

Even if it's true that moral facts in fact are necessarily reason-giving, that claim amounts to a substantive theoretical position, not a pre-theoretical datum. The claim that moral facts are reason-giving is logically weaker than the claim that they are necessarily so. Why then think the latter is a firm default? Many naturalists argue that genuinely pre-theoretical data about the importance that our normative practices assign to moral facts can be accounted for even if our reasons to be moral obtain contingently. Such explanations typically take the following form. Given (i) some plausible assumptions about what kind of social and emotional factors are robust features of human social environments and psychology and (ii) some plausible first-order moral assumptions, it's a robust empirical generalization that moral agents have normative reason to do what's good and avoid what's bad (Brink 1984; Railton 1986; Boyd 1988; Copp 1995; Isserow ms). The kind of reasons internalism that underpins these explanations doesn't imply that our reasons for doing what morality tells us to do are merely instrumental (cf. Williams 1981). The contingency of such reasons also needn't be contingency on fragile preferences or desires. The relevant generalization may break down in anomalous cases - ideally coherent Caligulas or the like. But such individuals would be so far removed from most of us that it's unclear why their existence should be a threat to the normative authority of morality. It wouldn't be accidental that most of us, most of the time, have reason to do what morality tells us to do.

My aim here is to indicate how naturalists explain the importance that our normative practices assign to moral facts in terms of reasons to be moral that obtain as a matter of robust and deep contingency, not to defend these accounts. What I want to highlight is that such accounts can satisfy certain independently plausible conditions on normative authority which require less than treating moral facts as necessarily reason-giving. For instance, William FitzPatrick suggests that the significance of what various forms of non-normative inquiry (such as biology, psychology, and sociology) can contribute to moral inquiry "must be assessed through the lens of autonomous ethical reflection on our life and experience" because "nothing presented to a rational agent in any other way could be authoritative for her" 
(FitzPatrick 2008, 172). Normative naturalists can well accept that assessing the significance of potential inputs into moral inquiry is a central task of normative thought and talk. Especially if we don't rely on NNR, non-normative representations of natural properties may not suffice for this task. Any field of inquiry seems "theory-dependent" in its reliance on auxiliary theoretical assumptions, including some drawn from that very field (Boyd 1988, 190, 207). For a simple example in ethics, consider a modest moral principle: no morally admirable person would instigate and oversee the deaths of millions of people. And consider a moral claim which some people accept: Hitler was a morally admirable person. These two moral claims jointly yield an empirical consequence: Hitler didn't instigate and oversee the deaths of millions of people. But it's an empirical fact that he did. So we know, on the basis of empirical test, that at least one of these moral claims must be rejected. ${ }^{20}$ The empirical constraint doesn't say which one to reject. But that's par for the course: claims are assessed in bundles, not singly in isolation. So naturalists can agree that autonomous ethical reflection is required to assess which moral claims we should reject.

A deadlock now threatens the debate about the JTD objection. It's dialectically inadmissible for the objection to presuppose that moral facts are necessarily or categorically reason-giving. But the objection fails under various weaker notions of authoritative normativity, such as those characterized in terms of deliverances of autonomous normative reflection. Naturalists may also be able to accommodate a robust sense in which genuine norms are inescapable. (For instance, they might adapt proposals from Woods 2018.) And they can accept that wrongness, for instance, is authoritatively normative in the sense that it involves violations of important standards which warrant blame, other things being equal (Copp 2020a). Whether normative properties are just too different from natural properties depends on what's packed into a notion of authoritative normativity which it would be dialectically admissible for the JTD objection to deploy. The jury's still out on that.

20 Nick Sturgeon used this example in an undergraduate lecture on normative ethics which I once sat in on. 


\section{Authoritative normativity in thought and talk}

I'll now offer a slightly sideways approach to the JTD objection. I'll sketch a kind of proof of concept that normative naturalism faces no distinctive trouble making sense of thought and talk involving authoritative normativity. I'll do this by showing how naturalists can make sense of a certain type of authoritatively normative concept if they so desire. Whatever trouble naturalism may face will be of a sort faced by other metaethical views as well. While I hope that the concept I'll focus on is representative, I won't be able to show that the strategy generalizes to further notions of authoritative normativity that I haven't discussed. ${ }^{21}$

This strategy speaks to the JTD objection even though the objection is normally framed in terms of normative facts and properties rather than terms or concepts. As noted in $\S 2$, there's a dispute about whether being normative is primarily a feature of terms and concepts, or of the facts and properties they express. On the one hand, if normative properties are normative because of some features of the terms or concepts that ascribe them, then making naturalist sense of authoritative normativity is primarily a task of making naturalist sense of thought and talk involving authoritative normativity. If normative properties instead are normative because of some features of non-representational reality, we would still expect our thought and talk about such properties somehow to reflect whatever connection to decision and action marks a fact or property as authoritatively normative. Either way, if naturalists can make sense of thought and talk involving authoritative normativity, then nothing in its nature shows that the properties ascribed by such thought and talk are just too different from (other)

21 Another limitation is that I set aside first-order questions about which standards or facts are authoritatively normative. For one such first-order account, see (Rowland forthcoming). That account seems compatible with normative naturalism. A broader question here is whether it's better to think of authoritatively normative oughts (if there are any) as exemplifying a distinct ought-concept (or concepts) or as combining an exemplification of some independently possessable ought-concept (MORAL OUGHT, or the like) with a higher-order property of being authoritatively normative in some sense (for this distinction, see (Howard and Laskowski ms)). I hope my discussion to be modifiable to fit either model. 
natural properties to be natural properties themselves. This should also enable naturalists to explain why such thought and talk might be not only indispensable for thinking about authoritatively normative facts, but also important. The strategy is available to both one-term and two-term naturalists. (The latter would need to show that normative concepts are indispensable for, for example, deliberation or normative knowledge even though everything that can be said in normative terms about what the world is like can also in principle be said in wholly non-normative terms. ${ }^{22}$ ) But it comes with one less headache to normative naturalists who aren't committed to NNR: making naturalist sense of thought and talk involving authoritative normativity doesn't require showing that the properties it ascribes can in principle be also ascribed in wholly non-normative terms.

I'll explain the strategy I have in mind in terms of an authoritatively normative concept individuated by its distinctive role in the deliberative activity of non-arbitrary selection. This is the concept Tristram McPherson labels PRACTICAL OUGHT: a normative concept which has distinctive authority because it's "the concept of a norm which is the norm to appeal to in the context of non-arbitrary selection" (McPherson 2018, 267; cf. McPherson 2020).$^{23}$ When morality requires one thing but prudence requires something else, a resolution of their relative importance had better be nonarbitrary, and a norm that provides such a solution would seem to lord over the norms whose conflict it resolves. This might be the concept that some call the concept of ought simpliciter. ${ }^{24}$ It looks like a dialectically admissible tool for assessing whether normative naturalism can make sense of how authoritative normativity figures in our normative thought and talk.

Normative naturalism has no distinctive trouble making sense of how this sort of authoritative normativity figures in language. The talk you

22 This is the standard two-term naturalist strategy. Its most common form is to say that normative concepts are distinguished by a kind of conceptual role which non-normative concepts are of a wrong kind to serve.

${ }^{23}$ I use small caps to denote concepts. To be clear, my discussion here concerns the concept McPherson (2018) dubs PRACTICAL OUGHT, not his particular analysis of it.

24 Some philosophers are skeptical of ought simpliciter (Baker 2018; Copp 2020b; Howard and Laskowski ms). If they're right, normative naturalism faces no challenge from authoritative normativity in this sense.

Organon F 28 (3) 2021: 505-530 
sometimes see of "the special nature of normative words" is misleading. There are no normative words (not in English anyway) in the strong sense of words that are conventionally associated with, specifically, authoritative normativity. Rather, there are words that can be used normatively, in various senses of 'normative'. Which sort of claim a given assertive utterance of a word like 'ought', 'wrong', or 'good' expresses depends on the context of utterance, in a potentially complex sort of way. ${ }^{25}$ In some contexts 'ought' expresses PRACTICAL OUGHT. But in many contexts it expresses forms of non-authoritative normativity that are (as we saw above) widely agreed to be naturalistically acceptable. The latter entails that the context-invariant features of what 'ought' means are compatible with normative naturalism. Nor does normative naturalism conflict with features specific to contexts in which 'ought' expresses PRACTICAL OUGHT, such as the notion of "the norm to appeal to" or the notion of non-arbitrary selection.

Getting the relevant ought into thought is slightly more fraught. One option is that authoritative normativity figures in ways of thinking about normative properties which don't amount to distinct concepts or modes of presentation for them but instead play some indispensable non-referential function. ${ }^{26}$ I'll instead explain how naturalists have no distinctive trouble making sense of a distinct concept like PRACTICAL OUGHT. Here's the key point: any concept like PRACTICAL OUGHT must involve an ordering of the items that are relevantly live options in the given context. The ought-structure is in general such that what you ought to do is one among the top options on the contextually relevant ordering of the relevantly live options. That's what falls out of the standard sort of descriptive semantics for 'ought' in deontic contexts, broadly in the vein of Kratzer (1991). There's no reason to think that PRACTICAL OUGHT is an exception. 'Ought' can be used to express it. More importantly, if PRACTICAL OUGHT didn't involve an ordering, it couldn't play its role in non-arbitrary selection when requirements of

25 In not saying more about this, I'm skipping many complex issues regarding the semantics and metasemantics of these terms and their context-sensitivity. In other work I argue that the practical role of words like 'ought' isn't a feature of their descriptive semantics or metasemantics (Väyrynen forthcoming).

${ }_{26}$ For such accounts, see (Copp 2018; 2020a) and (Laskowski 2019). For some objections, see (Bedke 2021). 
morality conflict with the law, when promoting the interests of one's beloved conflict with fairness, and so on. So a non-defective application of PRACTICAL OUGHT commits the thinker to there being a certain kind of ordering which somehow gets uniquely selected by the concept or its application in a context. (Uniqueness is required if that ordering is to be the norm to appeal to in non-arbitrary selection. In what follows, I'll simplify presentation by assuming that uniqueness is baked into non-arbitrariness.)

What ordering is this? Ought-concepts are individuated in part (though perhaps not wholly) by the orderings they involve. MORAL OUGHT and PRUDENTIAL OUGHT are different concepts if (though perhaps not only if) they rank options by different criteria. Structurally speaking PRACTICAL OUGHT looks no different; it's individuated in part in relation to an ordering (whichever it is) that provides a basis for successful non-arbitrary selection among the relevantly live options in the context. Content-wise, PRACTICAL OUGHT doesn't encode a specific ordering or its source. But MORAL OUGHT doesn't do so either; it's a substantive question what the correct moral standards are. So it's hardly distinctive of PRACTICAL OUGHT that specifying how the relevantly live options rank will require substantive normative inquiry and is subject to dispute and disagreement. Ought-structure in general and PRACTICAL OUGHT in particular may also do little to restrict what considerations may coherently be treated as relevant to what one practically ought to do. This concept's contribution to the content of thoughts that token it may accordingly be informatively fairly thin - something like a condition characterizable as ranking highly on an ordering, whichever it is, which provides a basis for successful non-arbitrary selection among the relevantly live options.

These are wholly general points about PRACTICAL OUGHT. As broadly structural points, they're largely neutral between a wide range of metaethical views, realist and antirealist alike. This should already lead us to expect that normative naturalism should have no distinctive trouble accounting for PRACTICAL OUGHT thoughts. But to check this, let's look at issues where different metaethical views might differ, ontology aside. There are issues in the philosophy of mind, such as what kind of mental state someone's in when they judge that they practically ought to do something. And there are issues in the metasemantics of normative concepts, such as in virtue of 
what factors PRACTICAL OUGHT comes to pick out the property of ranking highly among a set of live options on the relevant kind of ordering. ${ }^{27}$

As regards philosophy of mind, most naturalists would characterize the judgment that I practically ought to $\varphi$ as a belief that $\varphi$-ing ranks highly on the relevant kind of ordering. It isn't clear why there should be any deep puzzle as to how such a belief could serve the deliberative role of PRACTICAL OUGHT. ${ }^{28}$ If I believe that I practically ought to do something, I'm committed to thinking that a certain resolution to my practical situation is correct. That's just built into the ordering which induces that resolution. It's a further question whether I'm genuinely committed let alone motivated to act that way. Just as sharing a normative concept may not require a lot of uniformity in inputs to its application, it may not require a lot of uniformity in the practical upshots of its application (cf. Merli 2009).

As regards metasemantics, normative naturalists of course have work to do in explaining the reference of concepts like PRACTICAL OUGHT. If PRACTICAL OUGHT stands for ranking highly on a certain kind of ordering, there are questions about whether that property is natural and how PRACTICAL OUGHT comes to pick it out. Is its reference fixed by how its use is causally regulated, or its conceptual role, or the functions of the representational systems that use the concept, or some combination of these or other factors? How does the relevant mechanism fit with what makes a property natural, whether that be playing a causal role, being empirical, or something else? (This matters especially to one-term naturalists who need normative properties to meet the conditions for naturalness in their own right.) But these questions aren't special to PRACTICAL OUGHT. Whether and how normative concepts get to pick out natural properties just is the general metasemantic question for naturalism, just as whether and how they get to pick out nonnatural properties is the general metasemantic question for non-naturalism, and likewise for other views in normative metaphysics.

It's not clear why normative naturalists should be in any worse position than others in accounting specifically for PRACTICAL OUGHT thoughts. One

27 Or, perhaps, a property meeting a condition so characterized. I won't distinguish these below for simplicity.

28 Thus, I don't see why McPherson (2020, 1344-45) thinks there's a deep puzzle here for normative realists. 
consideration here is that this concept doesn't commit us to categorical reasons. The claim that successful non-arbitrary selection necessarily provides normative reasons for action is a substantive claim not built into the content of PRACTICAL OUGHT. Another consideration is that normative naturalism looks no worse off in ensuring that PRACTICAL OUGHT has an acceptably determinate representational content. ${ }^{29}$ For this concept to have a non-empty extension on any view, there must be an ordering which provides a basis for successful non-arbitrary selection among the relevantly live options in the context. Some vagueness aside, this should ensure sufficient determinacy in representational content. At minimum, it is not clear why failure of uniqueness should turn on whether this relation is a natural relation. That the content of the ordering is subject to ignorance, uncertainty, and disagreement also doesn't mean that PRACTICAL OUGHT thoughts lack acceptably determinate content. Finally, if PRACTICAL OUGHT stands for ranking highly on a certain kind of ordering, normative naturalists needn't worry about whether it can be represented in wholly non-normative terms unless they accept NNR. They can also agree that determining which properties normative concepts refer to may require first-order normative assumptions. ${ }^{30}$ There may be no normatively neutral way to determine whether GOOD refers to goodness even if goodness is a natural property, and likewise for PRACTICAL OUGHT.

In saying that it's not clear why normative naturalists should be any worse off here, I really don't mean to be bloody-minded. It remains a live question whether there is a natural property or relation which satisfies a condition like ranks highly on an ordering, whichever it is, which provides a basis for successful non-arbitrary selection among the relevantly live options in the given deliberative context, and does so in such a way that

29 McPherson $(2020,1346-51)$ argues that ensuring representational determinacy is a serious challenge to normative realists. Here I can pick up on only one dimension of the challenge he poses. However, some of the dimensions I bracket strike me as less troublesome, since McPherson takes as his foil an overly simple sort of causal metasemantics (simpler, say, than the epistemically constrained account in (Boyd 1988)). But see (Schroeter and Schroeter 2013).

30 I discuss this briefly in relation to Boyd's causal metasemantics in (Väyrynen 2019, 206-8). 
PRACTICAL OUGHT can be said to stand for that property. My point here is that there's no good reason why this sort of authoritatively normative property should be just too different from (other) natural properties to itself be natural, given that normative naturalism has no distinctive trouble making sense of thoughts involving it. It remains to be seen whether this strategy generalizes to other relevant authoritatively normative concepts besides PRACTICAL OUGHT. But on this proof of concept, issues facing normative naturalism wouldn't be distinctive. They would be just the same general issues that face any metasemantics for normative thought and talk.

\section{Conclusion}

My aim in this paper has been to contribute to debates about how normative properties might figure in our thought and talk if normative naturalism is true. First, I offered some improvements on Sturgeon's formulation of an assumption about representation of natural properties which I called Non-Normative Representability, and noted several objections to normative naturalism which presuppose NNR. Second, I offered some reasons, Sturgeon's and my own, why the truth of normative naturalism doesn't require NNR and why NNR is questionable enough for naturalists to have reason to keep their distance since they can. If that's right, the objections in question fall away. Third, I offered a slightly sideways approach to the "just too different" objection to normative naturalism. I first suggested that the objection loses some of its force if normative naturalism isn't committed to NNR and noted difficulties in specifying the notion of "genuine" or "authoritative" normativity which is the objection's primary concern. I then tried to make progress with a proof of concept that naturalists have no distinctive trouble making sense of thought and talk involving the relevant kind of authoritative normativity. While the strategy is compatible with NNR, its execution will prompt fewer headaches if normative naturalists don't count NNR among their commitments. I leave it for future work to assess how well the strategy I offer generalizes. ${ }^{31}$

31 I dedicate this paper to the memory of Nick Sturgeon, who was a member of my dissertation committee at Cornell University. I wrote it to highlight the significance 


\section{References}

Baker, Derek. 2018. "Skepticism About Ought Simpliciter." Oxford Studies in Metaethics 13: 230-52. DOI:10.1093/oso/9780198823841.003.0011

Bedke, Matthew S. 2021. "Naturalism and Normative Cognition." Philosophical Studies 178: 147-67. https://doi.org/10.1007/s11098-020-01425-y

Bloomfield, Paul. 2001. Moral Reality. Oxford University Press.

Boyd, Richard N. 1988. "How to Be a Moral Realist." In Essays on Moral Realism, edited by Geoffrey Sayre-McCord, 181-228. Cornell University Press.

Brink, David O. 1984. "Moral Realism and the Sceptical Arguments from Disagreement and Queerness." Australasian Journal of Philosophy 62 (2): 111-25. https://doi.org/10.1080/00048408412341311

Cline, Brendan. 2015. "Moral Explanations, Thick and Thin." Journal of Ethics and Social Philosophy 9 (2): 1-21. https://doi.org/10.26556/jesp.v9i2.89

Copp, David. 1995. Morality, Normativity, and Society. Oxford University Press.

Copp, David. 2003. "Why Naturalism?" Ethical Theory and Moral Practice 6: 179-200. https://doi.org/10.1023/A:1024420725408

Copp, David. 2018. "Realist Expressivism and the Fundamental Role of Normative Belief." Philosophical Studies 175: 1333-56. https://doi.org/10.1007/s11098017-0913-6

Copp, David. 2020a. "Just Too Different: Normative Properties and Natural Properties." Philosophical Studies 177: 263-86. https://doi.org/10.1007/s11098-0181189-1

Copp, David. 2020b. "Normative Pluralism and Skepticism About 'ought Simpliciter." In The Routledge Handbook of Practical Reason, edited by Ruth Chang and Kurt Sylvan, 416-37. Routledge.

Dancy, Jonathan. 2006. "Nonnaturalism." In The Oxford Handbook of Ethical Theory, edited by David Copp, 122-45. Oxford University Press.

Dowell, J. L., and David Sobel. 2017. "Advice for Non-Analytic Naturalists." In Reading Parfit: On What Matters, edited by Simon Kirchin,153-71. Routledge. Eklund, Matti. 2017. Choosing Normative Concepts. Oxford: Oxford University Press.

Enoch, David. 2011. Taking Morality Seriously. Oxford: Oxford University Press.

of some of Nick's observations about the commitments of normative naturalism which its critics often neglect. I'm grateful to David Copp, Camil Golub, Jessica Isserow, Gerald Lang, Richard Rowland, a work-in-progress group at University of Leeds, the participants of the Value in Language workshop, and two anonymous reviewers for helpful comments on earlier drafts, and to Dan Zeman for inviting me to contribute. 
Finlay, Stephen. 2019. "Defining Normativity." Dimensions of Normativity. New Essays on Metaethics and Jurisprudence, edited by David Plunkett, Scott J. Shapiro, and Kevin Toh, 187-219. Oxford: Oxford University Press.

FitzPatrick, William, J. 2008. "Robust Ethical Realism, Non-naturalism, and Normativity." Oxford Studies in Metaethics 3: 159-205.

Gibbard, Allan. 2003. Thinking How to Live. Cambridge, MA: Harvard University Press.

Harman, Gilbert. 1986. "Moral Explanations of Natural Facts: Can Moral Claims be Tested Against Moral Reality?" The Southern Journal of Philosophy 24 (S1: Spindel Supplement: Moral realism, edited by Norman Gillespie): 57-68. https://doi.org/10.1111/j.2041-6962.1986.tb01596.x

Howard, Nathan, Nicholas Laskowski. ms. "No Gods, No Masters, No Authoritative Normativity." Unpublished manuscript.

Isserow, Jessica. ms. "Naturalising Moral Naturalism." Unpublished manuscript.

Jackson, Frank. 1998. From Metaphysics to Ethics. Oxford University Press.

Kratzer, Angelika. 1991. "Modality." In Semantics, edited by Arnim von Stechow, and Dieter Wunderlich, 639-50. De Gruyter.

Laskowski, Nicholas. 2019. "The Sense of Incredibility in Ethics." Philosophical Studies 176: 93-115. https://doi.org/10.1007/s11098-017-1007-1

McPherson, Tristram. 2018. "Authoritatively Normative Concepts." Oxford Studies in Metaethics 13: 253-77. DOI:10.1093/oso/9780198823841.003.0012

McPherson, Tristram. 2020. "Deliberative Authority and Representational Determinacy: A Challenge for the Normative Realist." Ergo 6 (45): 1331-58. https://doi.org/10.3998/ergo.12405314.0006.045

Merli, David. 2009. "Possessing Moral Concepts." Philosophia 37: 535-56. https://doi.org/10.1007/s11406-009-9180-x

Moore, G. E. 1903. Principia Ethica. Cambridge University Press.

Nagel, Thomas. 1986. The View from Nowhere. Oxford University Press.

Paakkunainen, Hille. 2017. "The "Just Too Different" Objection to Normative Naturalism." Philosophy Compass 13 (2): 1-13. https://doi.org/10.1111/phc3.12473

Parfit, Derek. 2011. On What Matters (Vol. 2). Oxford University Press.

Railton, Peter. 1986. "Moral Realism." The Philosophical Review 95 (2): 163-207. https://doi.org/10.2307/2185589

Railton, Peter. 2018. "Naturalistic Realism in Metaethics." In The Routledge

Handbook of Metaethics, edited by Tristram McPherson, and David Plunkett, 43-57. Routledge.

Roberts, Debbie. 2013. "It's Evaluation, Only Thicker." In Thick Concepts, edited by Simon Kirchin, 78-96. Oxford University Press.

Rosen, Gideon. 2018. "Metaphysical Relations in Metaethics." In The Routledge Handbook of Metaethics, edited by Tristram McPherson, and David Plunkett, 151-69. Routledge. 
Rowland, Richard. forthcoming. "The Authoritative Normativity of Fitting Attitudes." Oxford Studies in Metaethics 17.

Shafer-Landau, Russ. 2003. Moral Realism. Oxford University Press.

Schroeter, Laura and Schroeter, François. 2013. "Normative Realism: Co-reference without Convergence?". Philosophers' Imprint (13): 1-24. http://hdl.handle.net/2027/spo.3521354.0013.013

Sinclair, Neil. 2011. "The Explanationist Argument for Moral Realism." Canadian Journal of Philosophy 41 (1): 1-24. https://doi.org/10.1353/cjp.2011.0005

Sterelny, Kim, and Ben Fraser. 2017. "Evolution and Moral Realism." The British Journal for the Philosophy of Science 68 (4): 981-06. https://doi.org/10.1093/bjps/axv060

Sturgeon, Nicholas L. 1985. "Moral Explanations." In Morality, Reason and Truth. New Essays on the Foundations of Ethics, edited by David Copp, and David Zimmerman, 49-78. Rowman \& Allanheld.

Sturgeon, Nicholas L. 1986. "Harman on Moral Explanations of Natural Facts." The Southern Journal of Philosophy 24 (S1: Spindel Supplement: Moral Realism, edited by Norman Gillespie): 69-78. https://doi.org/10.1111/j.20416962.1986.tb01597.x

Sturgeon, Nicholas L. 2003. "Moore on Ethical Naturalism." Ethics 113 (3): 52856. https://doi.org/10.1086/345627

Sturgeon, Nicholas L. 2006. "Ethical Naturalism." In The Oxford Handbook of Ethical Theory, edited by David Copp, 91-121. Oxford University Press.

Väyrynen, Pekka. 2009. "Normative Appeals to the Natural." Philosophy and Phenomenological Research 79 (2): 279-314. https://doi.org/10.1111/j.19331592.2009.00279.x

Väyrynen, Pekka. 2013. The Lewd, the Rude and the Nasty. A Study of Thick Concepts in Ethics. Oxford University Press.

Väyrynen, Pekka. 2014. "Shapelessness in Context." Nô̂s 48 (3): 573-93. https://doi.org/10.1111/j.1468-0068.2012.00877.x

Väyrynen, Pekka. 2019. "Normative Commitments in Metanormative Theory." In Methodology and Moral Philosophy, edited by Jussi Suikkanen, and Antti Kauppinen, 193-213. Routledge.

Väyrynen, Pekka. forthcoming. "Practical Commitment in Normative Discourse." Journal of Ethics and Social Philosophy.

Williams, Bernard. 1981. "Internal and External Reasons." In Moral Luck, 101-13. Cambridge University Press.

Woods, Jack. 2018. "The Authority of Formality." Oxford Studies in Metaethics 13: 207-29. DOI:10.1093/oso/9780198823841.003.0010 